\title{
Title: Personality: Distraction or driver in the diagnosis of depression?
}

Michael Berk ${ }^{1,2,3}$, Philip Boyce ${ }^{1,4}$, Amber Hamilton ${ }^{1,5,6,7}$, Grace Morris ${ }^{1,5,6,7}$, Tim Outhred $^{1,5,6,7}$, Pritha Das ${ }^{1,5,6,7}$, Darryl Bassett ${ }^{1,8}$, Bernhard T Baune ${ }^{1,9}$, Bill Lyndon ${ }^{1,6,10,11}$, Roger Mulder $^{1,12}$, Gordon Parker ${ }^{1,13,14}$, Ajeet B Singh ${ }^{1,2}$, Gin S Malhi ${ }^{1,5,6,7}$

${ }^{1}$ Mood Assessment and Classification (MAC) Committee. See footnote.

${ }^{2}$ School of Medicine, IMPACT Strategic Research Centre, Deakin University, Barwon Health, Geelong, Vic., Australia

${ }^{3}$ Orygen the National Centre of Excellence in Youth Mental Health and Orygen Research Centre, the Department of Psychiatry, and the Florey Institute for Neuroscience and Mental Health, the University of Melbourne, Melbourne, Vic., Australia

${ }^{4}$ Discipline of Psychiatry, Sydney Medical School, Westmead Clinical School, University of Sydney, Sydney, NSW, Australia

${ }^{5}$ Academic Department of Psychiatry, Northern Sydney Local Health District, St Leonards, NSW, Australia

${ }^{6}$ Sydney Medical School Northern, University of Sydney, Sydney, NSW, Australia

${ }^{7}$ CADE Clinic, Royal North Shore Hospital, Northern Sydney Local Health District, St

Leonards, NSW, Australia

${ }^{8}$ Private Practice in Psychiatry and Division of Psychiatry, the University of Western

Australia, Crawley, WA, Australia

${ }^{9}$ Discipline of Psychiatry, University of Adelaide, Adelaide, SA, Australia

${ }^{10}$ Mood Disorders Unit, Northside Clinic, Greenwich, NSW, Australia

${ }^{11}$ ECT Services Northside Group Hospitals, Greenwich, NSW, Australia

${ }^{12}$ Department of Psychological Medicine, University of Otago - Christchurch, Christchurch, New Zealand

${ }^{13}$ School of Psychiatry, University of New South Wales, Sydney, NSW, Australia

${ }^{14}$ Black Dog Institute, Sydney, NSW, Australia

Correspondence: Gin S Malhi, MAC Committee Chair, CADE Clinic, Academic Department of Psychiatry, Level 3, Main Building, RNSH, St Leonards, Sydney, NSW 2065, Australia.gin.malhi@sydney.edu.au

Footnote: The Mood Assessment and Classification (MAC) Committee comprised academic psychiatrists with clinical expertise in the management of mood disorders and researchers with an interest in depression and bipolar disorders. The independently convened committee specifically targeted contentious aspects of mood disorders diagnosis and assessment with the express aim of informing clinical practice and future research. Members of the committee held one face to face meeting in Sydney (Australia) to discuss the issues in depth and agree upon outcomes. These were then developed further via email correspondence.

This is the author manuscript accepted for publication and has undergone full peer review but has not been through the copyediting, typesetting, pagination and proofreading process, which may lead to differences between this version and the Version of Record. Please cite this article as doi: $10.1002 / \mathrm{pmh} .1411$ 
This brief commentary argues that we need to consider the role of personality as a central part of our understanding of clinical and research models of depressed mood. Clinically, those with dysfunctional personality traits or disorders typically present with mood and/or anxiety symptoms consequent to their difficulties in adjustment. This confounds assessment and management of people presenting with depressed mood when simple unitary conceptualisations of depression are used together with associated algorithm based management plans.

In this context, despite the availability of a range of seemingly effective and safe treatments, depression as currently defined remains the largest cause of disability in younger adults, with its prevalence in developed countries, remaining static or even rising (1). Within many developed countries, antidepressant use is increasing, with prescription rates in Australia approaching $20 \%$ in population studies (2). Psychosocial therapies have never been more accessible and in Australia, access is advanced through government-subsidised programs such as the Better Access program, as well as easily available and often free global internetbased interventions. Although it is true that many people with depression still go untreated or do not receive treatment that is concordant with accepted standards, some do receive treatment concordant current guidelines for the diverse forms in which depression manifests (3). Nonetheless, the unperturbed prevalence of depression despite the overall advances in management raises the question as to what elements of the equation are missing.

An overarching and fundamental issue is the heterogeneity of depression, in particular the difference between 'clinical depression' and 'normal unhappiness'. Mood, as an experience, includes transient sadness in response to an untoward event and is a normative and adaptive response to adversity. Physiologically, depressed mood acts as a brake on maladaptive behaviour or facilitates adjustment to loss as part of the grieving process. It extends to persistent unhappiness as a response to enduring stressors or maladaptive coping - often the expression of a maladaptive personality style. Least common is the clinical syndrome of depression with its accompanying symptoms and marked functional impairment as well as the distinct disorder of melancholia. In this context, use of the term depression has expanded in recent years to encompass a broader spectrum of human unhappiness, while the hurdle to reach a diagnostic level in practice has been simultaneously lowered. Consequently the term 'depression' has begun to lose meaning and specificity, similar to 'neurosis', which fell out of use for lack of explicitness.

Reflecting this heterogeneity, there are many paths to the spectrum spanning unhappiness to clinical depression. Critical drivers are early life stressors, trauma and neglect as well as socio-economic problems, which have consequent lifelong impacts on emotion regulation, attachment style and underlying schemas and thus on personality development. Other risk pathways include medical comorbidities, lifestyle risk factors (substance use, smoking, diet and physical activity), bullying, intimate partner violence, stress, as well as genetic contributions. However, personality styles are particularly pertinent, as these lifelong traits of 
dysfunctional behaviour impact domains critical to happiness - work, social and interpersonal functioning.

Population studies show that the prevalence of threshold personality disorder vary from 5 $6 \%,(4,5)$ whereas dysfunctional personality traits that do not meet criteria for threshold classification are even more prevalent. Many individuals with dysfunctional personality traits may find it more difficult to regulate emotion and manifest dysfunctional attitudes and behaviours interacting with anxiogenic and depressogenic thought patterns under the frequently stressful or suboptimal conditions that characterise life. Indeed, people with dysfunctional personality traits or disorders (and those with high levels of neuroticism) typically present clinically with a mix of mood and anxiety symptoms and dysphoria that arise from their difficulties in adjustment that at face value can resemble more intransigent major depressive disorder. Dysphoric or depressed mood is the prototypic presentation of people with personality disorder, notwithstanding the heterogeneity of the umbrella of personality and its protean manifestations. It needs to be noted that the dysphoria and depression associated with borderline personality for example is subtly qualitatively different from that of major depressive disorder, often incorporating feelings of emptiness, loneliness and shame as well as alexithymia $(6,7)$.

The presence of personality disorder (and personality dysfunction) therefore complicates the management of mood disorders. Critically, when personality traits or disorder is a major factor contributing to depression, it is less likely to respond to medications that target the putative biological underpinnings of depression, when this may not be the principal driver of low mood. The presence of even one borderline personality trait seemingly worsens the prognosis of mood disorders (8). Non-adherence is more common, the therapeutic alliance more complex, treatment response more limited and the prognosis more guarded (9). Indeed, personality factors tend to be concentrated in the subgroup of individuals presenting with refractory depression. Personality disorder comorbidity is a driver of poorer outcomes in people with concurrent medical disorders and drives greater health service utilisation (10).

This takes us back to the nosology of depression itself. If we assume that the depression rubric as currently construed is too non-specific (and with the threshold set too low) to embody the unitary construct validity that the DSM and ICD classifications imply, then we may have to redefine what we mean by 'clinical depression'. Historically, there have been many attempts to subtype depression with varying degrees of success, but for the purposes of this argument, the key issue is the contribution of concurrent personality style. DSM-III put personality on a separate axis to depression, where it was relegated to a second tier, in contrast to the so-called "primary" disorders. However, that classification at least accepted that personality is a domain that could act in consort with axis one issues. DSM-5 removed the multi-axial formulation, but this does not mean that they are inconsequential for treatment. There is a danger that with a focus on axis I disorders in clinical practice, we may 
miss a consideration that could be vital to effective treatment of complex mood problems. We may be regretting the loss of axis II.

So where do we go from here? Personality arguably has a more central position in the genesis of depressed mood than many current models acknowledge. Pragmatically, using either DSM or ICD nosology or psychological models, a description of personality both at trait level (such as neuroticism) or threshold disorder, can inform understanding of depressed mood (e.g., its source, manifestations, and adaptive or maladaptive reactions), and should be routine in practice.

We further argue for the benefit of adopting or incorporating a formulation-based approach that incorporates personality style and/or disorder. The use of personality and developmentally informed clinical formulations adds qualitative depth to clinical understanding. This is normative in some countries and settings, but not internationally. A formulation which includes personality would facilitate treatment involving psychotherapy, aimed at equipping people with personality dysfunction with more personalised adaptive regulation and coping skills to lead more fulfilling lives (11). This formulation based approach could help with structuring relevant aspects of lifestyle (e.g., occupations, substance use), and offer more meaningful predictions of prognosis (12). Unfortunately our treatments for personality dysfunction are complex and not widely accessible (13) and many patients with personality/depression interactions risk becoming chronic and seemingly treatment resistant, receiving copious treatment for little benefit and great cost. Awareness of this risk might mitigate inappropriate use of medications and/or health care services (e.g., inpatient care). Formulation has been criticised for lacking inter-rater reliability, which is probably true, but symptom checklists that form the DSM categorisation of depression also have poor inter-rater reliability in field studies (14).

Some researchers have proposed personality-based non-melancholic depressive subtypes (15). While such a model has clear face validity in the context of this argument, such models remain to be validated to the standards required for universal clinical application.

The nub of the argument is that it is not possible, or desirable, to conflate depression as a unitary construct without understanding its diverse manifestations and aetiological pathways. In this context personality is possibly the most important driver at the population and clinical level. We perhaps need to define what is normal - with additional criteria that could define 'non-pathological' depression - and accept that often, unhappiness is commonly a normal reaction to stressful and distressing life experiences. Our consumer society frequently does not allow for realistic expectations of life - driving people to medicalise life and unhappiness. Society similarly increasingly sees stress as uniformly pathogenic, losing sight of the fact that the major path to resilience is serially coping and adjusting to life's vicissitudes. Educating health professionals about the spectrum of mood spanning grief and dysphoria in response to life's vagaries including the role of personality, and frank depressive illness and their 
differential management may thus be a key intervention. Research to assist in more accurately parsing these is needed.

If this argument is true, and personality is a preeminent driver of mood symptoms at a population level, then our individual level clinical expectations of treatment, informed by these epidemiology and public health data, need to be substantially different (16). As a trait and lifelong phenotype, it is not possible to eliminate the impact of personality at a population level, and the failure of widespread use of antidepressants and psychotherapy to treat the protean manifestations of human unhappiness at a population level should be expected. We should be far more parsimonious in our expectations and promises. We should equally guard against nihilism, as there remain many people who are greatly helped by available therapies. Key elements for progress include research towards the elusive target of stratification and personalisation of treatment choice, and translation of this into clinical practice by adding personality as an integral element of the construct of depression (17). In conclusion, we recommend that the assessment of depression should include routine assessment of personality structure. 


\section{Acknowledgments}

The MAC Project was supported logistically by Servier who provided financial assistance with travel and accommodation for those MAC Committee members travelling interstate or overseas to attend the meeting in Sydney (held on $18^{\text {th }}$ March 2017). Members of the committee were not paid to participate in this project and Servier had no input into the content, format or outputs from this project. MB is supported by a NHMRC Senior Principal Research Fellowship (1059660).

\section{Conflict of Interest}

The authors have no competing interests to declare.

\section{References}

1. Jorm AF, Patten SB, Brugha TS, Mojtabai R. Has increased provision of treatment reduced the prevalence of common mental disorders? Review of the evidence from four countries. World Psychiatry. 2017;16:90-9.

2. Stuart AL, Mohebbi M, Pasco JA, Quirk SE, Brennan-Olsen SL, Berk M, Williams LJ. Pattern of psychotropic medication use over two decades in Australian women. Aust N Z J Psychiatry 2017;5:1212-1219. d

3. Thornicroft G, Chatterji S, Evans-Lacko S, Gruber M, Sampson N, Aguilar-Gaxiola S, Al-Hamzawi A, Alonso J, Andrade L, Borges G, Bruffaerts R. Undertreatment of people with major depressive disorder in 21 countries. The British Journal of Psychiatry. 2017;210:119-24.

4. Coid J, Yang M, Tyrer P, Roberts A, Ullrich S. Prevalence and correlates of personality disorder in Great Britain. The British Journal of Psychiatry. 2006;188:423-31.

5. Huang Y, Kotov R, De Girolamo G, Preti A, Angermeyer M, Benjet C, Demyttenaere K, De Graaf R, Gureje O, Karam AN, Lee S. DSM-IV personality disorders in the WHO World Mental Health Surveys. The British Journal of Psychiatry. 2009;195:46-53.

6. Meaney R, Hasking P, Reupert A. Borderline Personality Disorder Symptoms in College Students: The Complex Interplay between Alexithymia, Emotional Dysregulation and Rumination. PLoS One. 2016;11(6):e0157294.

7. Ellison WD, Rosenstein L, Chelminski I, Dalrymple K, Zimmerman M. The Clinical Significance of Single Features of Borderline Personality Disorder: Anger, Affective 
Instability, Impulsivity, and Chronic Emptiness in Psychiatric Outpatients. J Pers Disord. 2016;30:261-70.

8. Zimmerman M, Chelminski I, Young D, Dalrymple K, Martinez J. Does the presence of one feature of borderline personality disorder have clinical significance? Implications for dimensional ratings of personality disorders. J Clin Psychiatry 2012; 73:8-12.

9. Newton-Howes G, Tyrer P, Johnson T, Mulder R, Kool S, Dekker J, et al. Influence of personality on the outcome of treatment in depression: systematic review and metaanalysis. Journal of Personality Disorders. 2014;28:577-93.

10. Quirk SE, El-Gabalawy R, Brennan SL, et al. Personality disorders and physical comorbidities in adults from the United States: data from the National Epidemiologic Survey on Alcohol and Related Conditions. Soc Psychiatry Psychiatr Epidemiol 2015;50:807-20.

11. Choi-Kain LW, Finch E F, Masland S R, Jenkins JA, Unruh B T. What Works in the Treatment of Borderline Personality Disorder. Current Behavioral Neuroscience Reports 2017; 4: 21-30.

12. Macneil CA, Hasty MK, Conus P, Berk M. Is diagnosis enough to guide interventions in mental health? Using case formulation in clinical practice. BMC Med. 2012 Sep 27;10:111.

13. French L.R.M., Turner K.M., Dawson S., Moran P.. Psychological treatment of depression and anxiety in patients with co-morbid personality disorder: A scoping study of trial evidence. Personality and Mental Health 2017;11:101-117.

14. Regier DA, Narrow WE, Clarke DE, Kraemer HC, Kuramonto SJ, Kuhl EA, Kupfer DJ. DSM-5 Field Trials in the United States and Canada, Part II: Test-Retest Reliability of Selected Categorical Diagnoses. Am J Psychiatry 2013; 170:59-70.

15. Parker G, Manicavasagar V. Modelling and managing the depressive disorders: a clinical guide: Cambridge University Press; 2005.

16. Quirk SE, Williams LJ, Chanen AM, Berk M. Personality disorder and population mental health. The lancet Psychiatry. 2015;2:201-2

17. Tyrer P. Tyrer H, Yang M, Guo B. Long-term impact of temporary and persistent personality disorder on anxiety and depressive disorders. Personality and Mental Health 2016; 10:76-83. 


\section{University Library}

\section{- M M N E R VA A gateway to Melbourne's research publications}

Minerva Access is the Institutional Repository of The University of Melbourne

Author/s:

Berk, M;Boyce, P;Hamilton, A;Morris, G;Outhred, T;Das, P;Bassett, D;Baune, BT;Lyndon, B;Mulder, R;Parker, G;Singh, AB;Malhi, GS

Title:

Personality: Distraction or driver in the diagnosis of depression

Date:

2018-05-01

\section{Citation:}

Berk, M., Boyce, P., Hamilton, A., Morris, G., Outhred, T., Das, P., Bassett, D., Baune, B. T., Lyndon, B., Mulder, R., Parker, G., Singh, A. B. \& Malhi, G. S. (2018). Personality: Distraction or driver in the diagnosis of depression. PERSONALITY AND MENTAL HEALTH, 12 (2), pp.126-130. https://doi.org/10.1002/pmh.1411.

Persistent Link:

http://hdl.handle.net/11343/283653 